\title{
Long-Term Quality of Prescription for ST-Segment Elevation Myocardial Infarction (STEMI) Patients: A Real World 1-Year Follow-Up Study
}

\author{
Christel Bruggmann ${ }^{1,2}(1) \cdot$ Juan F. Iglesias ${ }^{3} \cdot$ Marianne Gex-Fabry $^{4} \cdot$ Rachel Fesselet $^{5} \cdot$ Pierre Vogt $^{5}$. \\ Farshid Sadeghipour $^{1,2} \cdot$ Pierre Voirol $^{1,2}$
}

Published online: 12 July 2019

(c) The Author(s) 2019

\begin{abstract}
Aim American and European associations of cardiology published specific guidelines about recommended drugs for secondary prevention in ST-segment elevation myocardial infarction (STEMI) patients. Our aim was to assess whether drug prescription for STEMI patients was in accordance with the guidelines at discharge and after 1 year.

Method We used data of 361 patients admitted for STEMI in a tertiary hospital in Switzerland from 2014 to 2016. We assessed the adequacy of prescription of recommended drugs at two time points: discharge and after 1 year. Medications assessed were aspirin, P2Y12 inhibitors, statin, angiotensin-converting enzyme inhibitors (ACEIs)/angiotensin receptor blockers (ARBs) and $\beta$-blockers. We took into account several criteria like statin dosage (low versus high intensity) and presence of contraindication for consideration of optimal therapy. Predictors of incomplete prescription of guideline medications were then assessed with multivariate logistic regression models.

Results From discharge $(n=358)$ to 1-year follow-up $(n=303)$, rate of optimal prescription was reduced from 98.6 to 91.7\% for aspirin, from 93.9 to $79.1 \%$ for P2Y 12 inhibitors, from 83.8 to $65.7 \%$ for statins, from 98.6 to $95.6 \%$ for ACEIs/ ARBs, and from 97.1 to $96.9 \%$ for $\beta$-blockers. Predictors of incomplete prescription of guideline medications at discharge were female sex (odds ratio [OR] 2.54, $p=0.007$ ), active or former smoker status (OR 2.29, $p=0.017$ ), multivessel disease (OR 2.07, $p=0.022$ ), left ventricular ejection fraction $<40 \%$ (OR 2.49, $p=0.008$ ), and transfer to cardiac surgery (OR 9.66, $p=0.018$ ). At 1 year, age $>65$ (OR 1.92, $p=0.036$ ) remained the only significant predictor.

Conclusion The present study showed a high prescription rate of guideline-recommended medications in a referral center for primary percutaneous coronary intervention. At discharge, women and co-morbid patients were at the highest risk of incomplete prescription of guideline medications, whereas long-term prescription was suboptimal for elderly. A drug lacking at time of discharge was rarely introduced within the year, which underscores the paramount importance of optimal prescription at time of discharge. Strategies like implementing a standardized prescription could reduce the proportion of suboptimal prescription. It could therefore be one way to improve the long-term quality of care of our patients to the highest level. This study used local data from AMIS Plus-National Registry of Acute Myocardial Infarction in Switzerland (NCT01305785).
\end{abstract}

\section{Introduction}

Acute coronary syndrome (ACS) remains a leading cause of morbi-mortality in developed countries [1,2]. Among the three types of ACS [ST-segment elevation myocardial

Electronic supplementary material The online version of this article (https://doi.org/10.1007/s40256-019-00361-5) contains supplementary material, which is available to authorized users.

Christel Bruggmann

Christel.Bruggmann@chuv.ch

Extended author information available on the last page of the article infarction (STEMI), non-ST-elevation myocardial infarction (NSTEMI) and unstable angina (UA)], STEMI leads to the highest rate of death over the short term [3,4]. Moreover, survivors of a first event remain at increased risk for subsequent cardiovascular events such as death, recurrent myocardial infarction (MI), heart failure, arrhythmia, angina, and stroke [5]. Thus, secondary prevention has become increasingly important in the care of STEMI patients.

Effective secondary prevention measures include participation in a cardio-rehabilitation program, lifestyle modification, and use of a chronic cardioprotective drug regimen. Several randomized controlled studies have shown that use 


\section{Key Points}

The prescription rate of recommended drugs for the secondary prevention of acute coronary syndrome (ACS) has become a criterion to assess the quality of care in hospitals around the world. We found an optimal prescription rate of $74.3 \%$ at discharge in a tertiary hospital in Switzerland, which is higher than most results from other ACS registries.

The most important finding of our study is that adherence to guideline-recommended prescriptions decreased within the first year after ACS. We showed that this reduction was mostly due to a decrease in the dose of statin and early discontinuation of P2Y12 inhibitor. We also demonstrated that a drug which is lacking at the time of discharge without contraindication was rarely prescribed by general practitioners within the year.

These findings highlight the paramount importance of prescriptions at the time of hospital discharge. It is critical to focus on populations at increased risk of not receiving guideline-recommended medications and implement a standardized prescribing protocol for ACS patients at hospital discharge.

and continued use of recommended drugs after an ACS are associated with improved clinical outcomes and decreased risk for complications $[6,7]$. Current guidelines from the European Society of Cardiology (ESC) and the American College of Cardiology/American Heart Association (ACCF/ AHA) recommend a drug regimen for long-term therapy for STEMI patients undergoing percutaneous coronary intervention (PCI). This drug regimen includes lifelong aspirin and high-intensity statin, in addition to a P2Y12 inhibitor for up to 1 year. Depending on the guidelines, a $\beta$-blocker (BB) and an angiotensin-converting enzyme inhibitor (ACEI) or angiotensin receptor blocker (ARB) are recommended in specific conditions [8-12].

A recent French study with more than 5000 STEMI patients showed that around $40 \%$ of STEMI patients were undertreated [13]. This had clinical consequences, as undertreated patients had significantly higher 1-year mortality. In Switzerland, a few studies have already evaluated drug prescription for ACS patients at discharge, and one study assessed prescription over the long term [14-16]. All these studies showed a high adherence to guidelines, but none of them assessed statin intensity and the specific P2Y12 inhibitor prescribed, which are also important factors for optimal drug prescription assessment. Quality measures defined by the AHA for acute myocardial infarction (AMI) include the prescription of aspirin at hospital discharge, the use of an
ACEI or ARB if the patient has a left ventricular ejection fraction (LVEF) below $40 \%$ and the prescription of $\mathrm{BBs}$ [17]. Schiele et al., who suggested some quality indicators for AMI, included the prescription of a high dose of statin as a quality indicator for secondary prevention [18]. In an era where hospital performance is measured with quality indicators, it is essential to evaluate the prescription pattern of our hospitals.

Therefore, to add knowledge about the quality of care in developed countries, we conducted a single-center study in a Swiss tertiary hospital with percutaneous intervention (PCI) facilities and sought to ascertain whether guideline-recommended drugs were prescribed to STEMI patients. To fill the gaps of many studies about optimal prescription after ACS, we not only assessed prescription at discharge but also after 1 year. Information on long-term prescription is essential to evaluate the quality of care of ACS patients. With these data, our objective was first to assess the quality of prescriptions and then to identify characteristics of patients who were less likely to receive an optimal prescription. Our final goal was to suggest a solution to enhance the quality of prescriptions which could be adapted for use in other developed countries.

\section{Methods}

This study was a prospective observational study that assessed prescription of medication for STEMI patients at the time of discharge from a tertiary university hospital and after a 1-year period. We also had access to the discharge letters and discharge prescriptions from the files of patients transferred to a regional hospital after PCI.

The study was approved in 2005 by the local ethics committee as part of the national AMIS Plus registry, which is a national prospective registry of patients with ACS admitted to participating hospitals in Switzerland. The Centre Hospitalier Universitaire Vaudois (CHUV) has been considered a local center since 2005, and all data used in this study were obtained from the local database.

\subsection{Patient Population}

Patients were screened during the period from April 15, 2014 through April 15, 2016. Patients aged $\geq 18$ years and diagnosed with STEMI were included if they had capacity for discernment and provided written consent. Diagnosis of STEMI required clinical signs of characteristic retrosternal pain for $<12 \mathrm{~h}$ and electrocardiography showing ST-segment elevation in more than two contiguous derivations, a new bundle branch block, or ST-segment depression $\geq 0.5 \mathrm{~mm}$ in the V1-V3 leads.

After screening, we excluded patients with a final diagnosis other than STEMI (e.g., NSTEMI, Takotsubo syndrome, 
pericarditis, Prinzmetal angina), those with communication issues (e.g., inability to speak French or English, difficulties with elocution), those with a lack of capacity for discernment, and patients lacking consent for participation. Patients anticipated to be not reachable after 1 year (e.g., patients who did not live in Switzerland or who were homeless) were also excluded.

\subsection{Data Analysis}

Clinical research nurses screened all patients admitted for STEMI and met them once screened. The nurses were dedicated to clinical research and did not work as nurses in the cardiac unit. If the patient agreed to participate in the study, nurses prospectively collected baseline data including general information (age, sex, weight, and height), previous adverse drug event, allergies, intolerance to drugs, lab values, cardiovascular risk factors, comorbidities, diagnosis, therapeutic strategy with drug prescriptions, and discharge information (including discharge drug prescription). About 1 year after PCI, a clinical research nurse or a clinical research pharmacist contacted each participant by phone to collect data related to participation in cardio-rehabilitation, lifestyle changes, and current medical care (including all medication prescribed, with doses).

\subsection{Outcomes}

The primary outcome was the adequacy of prescription at discharge and at 1 year. Each drug category was defined as optimal or non-optimal prescription according to the following criteria: aspirin for all patients, ticagrelor or prasugrel as a P2Y12 inhibitor [or clopidogrel if concomitant prescription of oral anticoagulant (OAC) or high risk of bleeding], high-dose statin (e.g., atorvastatin 40-80 mg, rosuvastatin 20-40 mg), BB if the patient had post-AMI LVEF $<40 \%$, and ACEI/ARB if the patient had $\mathrm{LVEF}<40 \%$ or diabetes. This implies that the non-prescription of a BB to a patient with $\mathrm{LVEF} \geq 40 \%$ was considered as optimal, as well as the non-prescription of an ACEI/ARB to a patient without diabetes nor reduced LVEF.

The same criteria were used for assessment at the 1-year follow-up. However, duration of dual antiplatelet therapy (DAPT) with aspirin and a P2Y12 inhibitor for $\geq 12$ months was required for consideration as optimal therapy. We included reason for non-prescription in our analysis at discharge, and we presented results as adjusted prescription rate. Reasons for non-prescription accepted were history of life-threatening bleeding for aspirin, hypotension (systolic blood pressure $<100 \mathrm{mmHg}$ ) or acute renal failure (based on Kidney Disease: Improving Global Outcomes [KDIGO] criteria [19]) for ACEI/ARB, bradycardia ( $<50$ beats/min), second- or third-degree atrio-ventricular block, hypotension for BB, history of life-threatening bleeding, coagulopathy or thrombocytopenia for P2Y12 inhibitor (and prior stroke or age $\geq 75$ years for prasugrel) and history of myopathy, rhabdomyolysis or severe hepatic impairment (transaminase elevation of more than twofold the highest normal value) for statins. Reasons for non-prescription were assessed with the discharge letter.

At 1 year, we asked for the complete medication regimen of the patient to assess if any OAC [vitamin $\mathrm{K}$ antagonist (VKA) or direct oral anticoagulant (DOAC)] had been prescribed during the follow-up. In the case of an OAC introduction, switch from ticagrelor to clopidogrel within the year was considered as optimal. During the phone interview with the patient, we asked him to look at his drug boxes and to read what was written on the boxes (drug name, dose). If the patient was not able to give the complete name of the drug or the dose (for example, if he was not at home at the time of the phone call), we called the prescriber or the pharmacy to obtain the complete information.

Secondary outcomes were readmission within the followup. Readmission and readmission reasons were assessed via a conversation with the patient at the time of the follow-up call. At the time of follow-up, we also checked for any readmissions in the electronic patient record and collected this information from the regional hospital.

\subsection{Statistical Analysis}

Descriptive statistics considered frequencies and percentages for categorical variables, and mean value and standard deviation (SD) for continuous variables. Rates of complete versus incomplete prescription of guideline medications at discharge were compared using the Chi square test for equal proportions for categorical variables and the two-sample Student's $t$ test for equal means for continuous variables. Factors associated with incomplete prescription of guideline medications were further investigated with univariate and multivariate logistic regression models. Unadjusted odds ratios (ORs) and adjusted odds ratios $\left(\mathrm{OR}_{\mathrm{adj}}\right)$ were estimated together with $95 \%$ confidence intervals (CIs). Candidate predictors included sex, age $>65$ years, body mass index $(\mathrm{BMI})>25 \mathrm{~kg} /$ $\mathrm{m}^{2}$, cardiovascular risk factors (active or former smoker, dyslipidemia, diabetes, and hypertension), comorbidity (yes/no), creatinine $>110 \mu \mathrm{mol} / \mathrm{L}, \mathrm{LVEF}<40 \%$, transfer to a cardiac surgery service, and previous episodes of AMI, coronary artery bypass graft (CABG), or multivessel coronary disease. All factors were added to the multivariate model. A similar strategy was used to study prescription adherence to guidelines after 1 year. The selection of the criteria was based on known influencers from literature and on results from univariate analyses. All statistics were computed using STATA version 14 (Stata Corporation, College Station, TX). All tests were two-tailed, with significance set at $p<0.05$. 


\section{Results}

\subsection{Study Population and Baseline Characteristics}

The flowchart of patients included during the study period is presented in Fig. 1, whereas baseline characteristics of the 361 patients included in the study are presented in Table 1.

The subgroup of 43 patients lost to follow-up was significantly younger than the group of patients ultimately included in the study ( $46.5 \%$ were aged $<55$ years, $p=0.02)$. None of the other baseline characteristics differed between groups (see Table S1 in the electronic supplementary material). For the 12 patients who died during follow-up, reasons for death were mainly unknown, and we did not have access to their current drug regimen soon before death. Patients who died during the 1-year study period were significantly older and overweight and more likely to have diabetes, hypertension, or plurivessel coronary disease. Prescriptions at discharge were not statistically different between patients who survived at 1 year and those who died within the study period (see Table S2 in the electronic supplementary material).

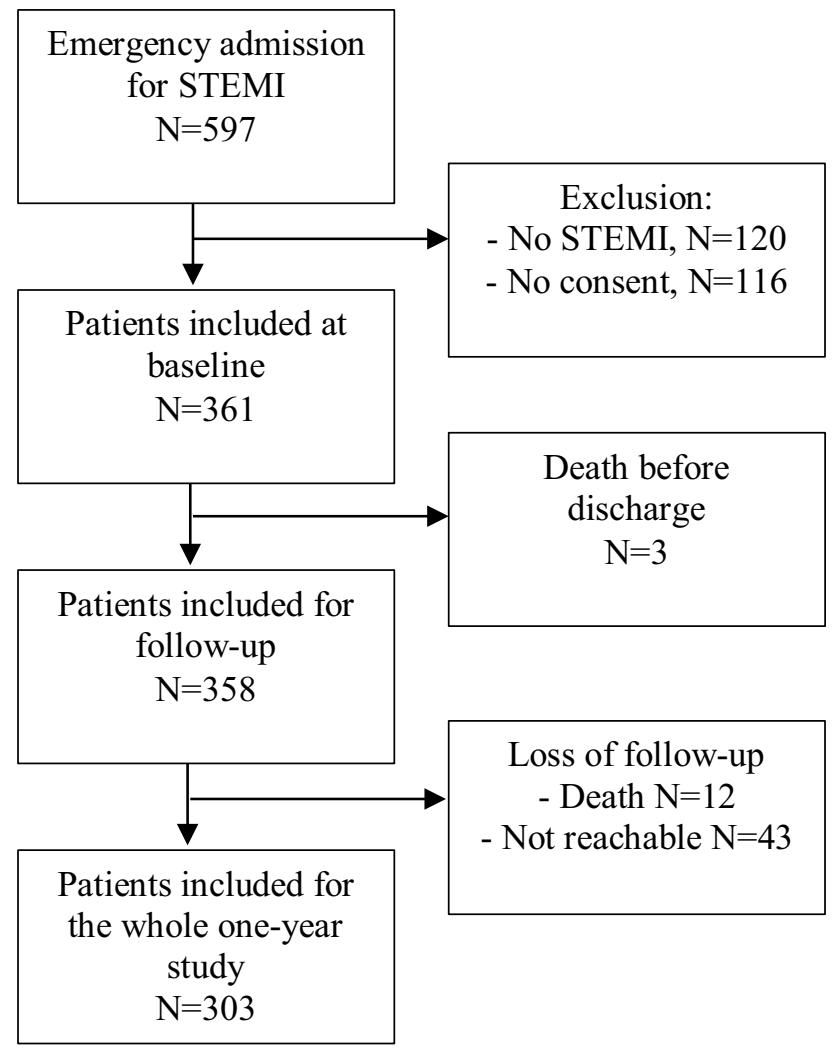

Fig. 1 Flow-chart of patients included from April 15, 2014 through April 15, 2016. STEMI ST-segment elevation myocardial infarction
Table 1 Baseline characteristics of study participants

\begin{tabular}{|c|c|}
\hline Variables & Frequency $(\%)$ \\
\hline \multicolumn{2}{|l|}{ Overall $(n=361)$} \\
\hline \multicolumn{2}{|l|}{ Demographic $(n=361)$} \\
\hline Women & $87(24.1)$ \\
\hline Age, years (mean (SD)) & $63.9(13.1)$ \\
\hline \multicolumn{2}{|l|}{ Age group } \\
\hline$<55 \mathrm{yr}$ & $95(26.3)$ \\
\hline $55-64$ yr & $95(26.3)$ \\
\hline $65-74$ yr & $95(26.3)$ \\
\hline$>75$ years & $76(21.1)$ \\
\hline \multicolumn{2}{|l|}{ BMI categories $(n=360)$} \\
\hline$<25 \mathrm{~kg} / \mathrm{m}^{2}$ & $135(37.5)$ \\
\hline $25-29.9 \mathrm{~kg} / \mathrm{m}^{2}$ & $150(41.7)$ \\
\hline$\geq 30 \mathrm{~kg} / \mathrm{m}^{2}$ & $75(20.8)$ \\
\hline \multicolumn{2}{|l|}{ Cardiovascular risk factors } \\
\hline \multicolumn{2}{|l|}{ Smoking categories $(n=357)$} \\
\hline Active smoker & $138(38.7)$ \\
\hline Former smoker & $102(28.6)$ \\
\hline Non-smoker & $117(32.8)$ \\
\hline Family history of CAD $(n=323)$ & $97(30.0)$ \\
\hline History of hypertension $(n=361)$ & $162(44.9)$ \\
\hline History of dyslipidemia $(n=355)$ & $215(60.6)$ \\
\hline History of diabetes mellitus $(n=359)$ & $53(14.8)$ \\
\hline \multicolumn{2}{|l|}{ Medical history } \\
\hline Prior AMI $(n=359)$ & $47(13.1)$ \\
\hline Prior CABG $(n=359)$ & $9(2.5)$ \\
\hline \multicolumn{2}{|l|}{ Coronary disease type $(n=361)$} \\
\hline Monovessel & $147(40.7)$ \\
\hline Bivessel & $121(33.5)$ \\
\hline Trivessel & $93(25.8)$ \\
\hline \multicolumn{2}{|l|}{ Therapeutic strategy $(n=361)$} \\
\hline Primary angioplasty & $352(97.5)$ \\
\hline CABG & $5(1.4)$ \\
\hline Conservative treatment & $4(1.1)$ \\
\hline \multicolumn{2}{|l|}{ Involved artery $(n=361)$} \\
\hline Right coronary artery & $215(59.6)$ \\
\hline Interventricular artery & $263(72.9)$ \\
\hline Left circumflex artery & $158(43.8)$ \\
\hline Ramus angularis artery & $5(1.4)$ \\
\hline Left main trunk & $24(6.6)$ \\
\hline CABG & $7(1.9)$ \\
\hline \multicolumn{2}{|l|}{ Number of stents $(n=361)$} \\
\hline 0 & $33(9.1)$ \\
\hline 1 & $214(59.3)$ \\
\hline 2 & $80(22.2)$ \\
\hline 3 or more & $34(9.4)$ \\
\hline \multicolumn{2}{|c|}{ Post-PCI intervention before discharge $(n=361)$} \\
\hline CABG & $7(1.9)$ \\
\hline Pacemaker implantation & $3(0.8)$ \\
\hline ICD implantation & $3(0.8)$ \\
\hline
\end{tabular}


Table 1 (continued)

\begin{tabular}{lc}
\hline Variables & Frequency $(\%)$ \\
\hline LVEF category $(\boldsymbol{n}=\mathbf{3 4 9})$ & \\
$<30 \%$ & $13(3.7)$ \\
$30-40 \%$ & $59(16.9)$ \\
$>40 \%$ & $277(79.4)$ \\
Destination at discharge $(\boldsymbol{n = 3 6 0})$ & $179(49.7)$ \\
Home & $172(47.8)$ \\
Peripheral hospital & $9(2.5)$ \\
Other in-hospital service & \\
\hline
\end{tabular}

$A M I$ acute myocardial infarction, $B M I$ body mass index, $C A B G$ coronary artery bypass grafting, $C A D$ coronary artery disease, $I C U$ intensive care unit, $P C I$ percutaneous coronary intervention, $I C D$ implantable cardioverter defibrillator, $L V E F$ left ventricular ejection fraction

\subsection{Adherence to Guidelines}

Figure 2 shows the adequacy of prescription of each recommended drug class at discharge and at 1-year follow-up. At discharge, rates of optimal prescription were $>90 \%$ for all drug classes except statin. After 1 year, this proportion was reduced for each class, but the decrease in magnitude was greatest for P2Y12 inhibitors and statins.

\subsection{Prescription Rate of BB and ACEI/ARB According to LVEF}

Figure 3 illustrates the proportion of patients receiving an ACEI/ARB or a BB according to LVEF. The proportion of patients receiving ACEI/ARB and/or BB was high, with $>75 \%$ of patients receiving the drug at discharge and at 1 year. The differences within the groups LVEF $\geq 40 \%$ versus $\mathrm{LVEF}<40 \%$ was not statistically significant. The rate of BB withdrawal from discharge to 1 year was $13.1 \%$ in the LVEF $\geq 40 \%$ subgroup (26 from 198 patients) and $8.3 \%$ in the LVEF $<40 \%$ subgroup (four from 48 patients). Reasons for withdrawal were side effect for four participants (13.3\%), non-adherence for two participants $(6.7 \%)$ and unknown for the remaining ones $(24 / 30 ; 80 \%)$. For ACEI/ARB, the rate of withdrawal was $16 \%$ in the $\mathrm{LVEF} \geq 40 \%$ subgroup (36 from 225 patients) and $11.5 \%$ in the LVEF $<40 \%$ subgroup (six from 52 patients). Reasons for withdrawal were side effect (hypotension, cough, tiredness) for eight patients (19.0\%), non-adherence for two patients $(4.8 \%)$ and unknown for the remaining participants $(76.2 \%)$.

\subsection{Changes Within the Year}

Changes in drug regimen within the year are presented in Table 2. The proportion of patients discharged with an optimal prescription and for whom a change within the year resulted in a suboptimal prescription was as follows: $7.4 \%$ for aspirin, $17.5 \%$ for P2Y12 inhibitor, $25.6 \%$ for statin, $4.1 \%$ for ACEI/ARB, and $1.4 \%$ for BB. Reasons for these changes were drug withdrawal within the year for aspirin, ACEI/ARB and BB. Different reasons explained changes from optimal prescription at discharge to suboptimal prescription at 1 year for P2Y12 inhibitors and statins: among 268 patients discharged with an optimal prescription of P2Y12 inhibitor, 19 patients $(7.1 \%)$ discontinued the drug earlier than 1 year, 19 (7.1\%) were switched from ticagrelor to clopidogrel without concomitant OAC prescription, nine (3.4\%) discontinued $\mathrm{OAC}$ after discharge and were not switched from clopidogrel to ticagrelor or prasugrel. Reasons for early discontinuation or drug switch were side effects in 12 patients (dyspnea, bleeding), three had a planned surgery or dental procedure, two reported to be not taking their drug, and one patient had a high hemorrhagic risk. The reason was unknown for the remaining participants $(n=33)$. Reasons for changing statins were drug withdrawal or drug dose reduction within the year. Among 251 patients prescribed high-dose statin therapy at discharge (three patients from 254 with optimal statin therapy had a contraindication for statin therapy), 19
Fig. 2 Rate of optimal prescription at discharge for each drug class $(n=358$ for aspirin, P2Y12 inhibitor and highintensity statin; $n=349$ for ACEI/ARB; $n=347$ for BB) and at 1 year $(n=303$ for aspirin and statin; $n=282$ for P2Y12; $n=297$ for ACEI/ARB; $n=295$ for $\mathrm{BB})$. $A C E I$ angiotensin-converting-enzyme inhibitor, $A R B$ angiotensin receptor blocker, $B B$ $\beta$-blocker, $L V E F$ left ventricular ejection fraction

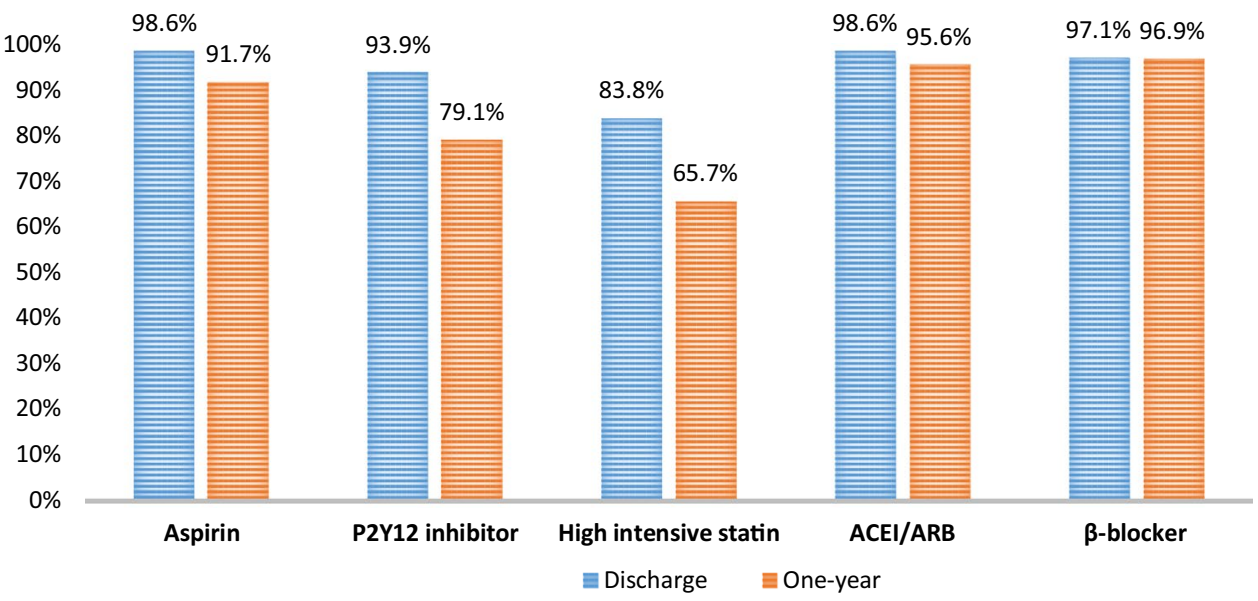


Fig. 3 Prescription rate of ACEI/ARB and BB at discharge and at 1 year, according to patient's LVEF after STEMI. Eleven patients with unknown LVEF at discharge and eight at 1 year. $A C E I$ angiotensinconverting-enzyme inhibitor, $A R B$ angiotensin receptor blocker, $B B \beta$-blocker, $L V E F$ left ventricular ejection fraction, STEMI ST-segment elevation myocardial infarction
LVEF $\geq 40 \%$ ( $n=276$ at discharge and 239 at one-year) $\quad$ LVEF $<40 \%$ ( $n=71$ at discharge and 56 at one-year)

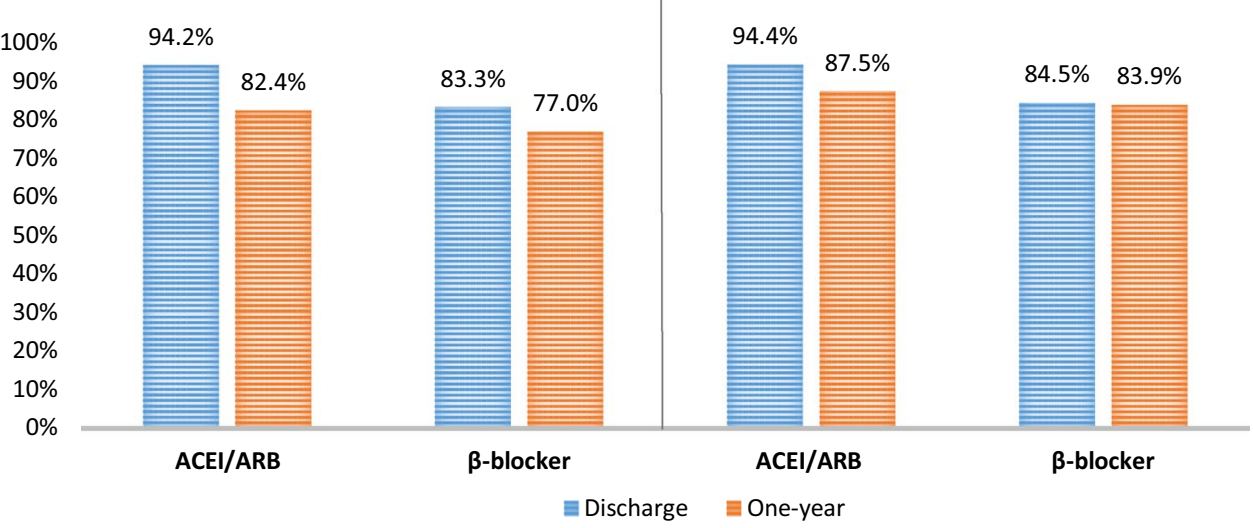

Table 2 Drug changes within the year

\begin{tabular}{|c|c|c|c|c|c|c|}
\hline & \multirow{2}{*}{$\begin{array}{l}\text { Optimal prescription at } \\
\text { discharge }(n) \\
n\end{array}$} & \multicolumn{2}{|c|}{$\begin{array}{l}\text { Suboptimal prescription } \\
\text { at 1-year; n (\%) }\end{array}$} & \multirow{2}{*}{$\begin{array}{l}\text { Suboptimal prescription } \\
\text { at discharge }(n) \\
n\end{array}$} & \multicolumn{2}{|c|}{$\begin{array}{l}\text { Optimal prescription } \\
\text { at } 1 \text {-year; } n(\%)\end{array}$} \\
\hline & & $n$ & $\%$ & & $n$ & $\%$ \\
\hline Aspirin $(n=303)$ & 299 & 22 & 7.4 & 4 & 1 & 25.0 \\
\hline P2Y12 inhibitor $\left(n=282^{\mathrm{a}}\right)$ & 268 & 47 & 17.5 & 14 & 2 & 14.3 \\
\hline High intensive statin $\left(n=300^{\mathrm{b}}\right)$ & 254 & 65 & 25.6 & 49 & 10 & 20.4 \\
\hline ACEI/ARB $\left(n=297^{c}\right)$ & 292 & 12 & 4.1 & 5 & 4 & 80.0 \\
\hline Beta-blocker $\left(n=295^{\mathrm{d}}\right)$ & 287 & 4 & 1.4 & 8 & 3 & 37.5 \\
\hline
\end{tabular}

a21 patients had an unknown duration of P2Y12 inhibitor

b 3 patients had a contraindication for statins

${ }^{\mathrm{c}} 6$ patients with unknown LVEF

d 8 patients with unknown LVEF

(7.6\%) discontinued the drug and $46(18.3 \%)$ received prescriptions for decreased doses within the year. Reasons for discontinuation or drug reduction were side effect for 13 patients $(20.0 \%)$, patient refusal for six patients $(9.2 \%)$, a low-density lipoprotein cholesterol (LDL-C) value in the target for two patients (3.1\%), and unknown for the rest of the participants (67.7\%).

Among patients with a suboptimal drug prescription at discharge, changes for an optimal prescription at 1 year were variable between drugs: an ACEI/ARB was introduced to $80 \%$ of the patients and aspirin to $25 \%$ of them. Statins were introduced or up-titrated to a high-intensity dose in $20.4 \%$ of the population.

\subsection{Proportion of Patients with an Optimal Drug Regimen According to Guidelines}

At discharge, 266 patients had received an optimal drug regimen as recommended (74.3\%). In the subgroup of patients with $\mathrm{LVEF} \geq 40 \%$ ( $n=276), 223(80.8 \%)$ received an optimal drug regimen, significantly more often than in the subgroup of patients with LVEF $<40 \%(n=71), 43$ $(60.6 \%)(p<0.001)$. After 1 year, the rate of optimal prescription in the whole population decreased to $49.1 \%$ (135 patients from 275 with complete data). Among patients with LVEF $\geq 40 \%(n=225), 117(52.0 \%)$ received an optimal drug regimen, whereas among patients with $\mathrm{LVEF}<40 \%$ $(n=50), 18(36.0 \%)$ received an optimal drug regimen. The difference between the two groups is statistically significant $(p=0.041)$.

\subsection{Predictors of Incomplete Adherence to Guidelines}

Predictors of incomplete adherence to guidelines at discharge and at 1 year were further investigated using univariate and multivariate logistic regression models (Table 3). The number of patients included in this table is lower than the whole collective of patients we had for the analysis. This discrepancy is due to missing data for some predictors (i.e., 
dyslipidemia, smoking status, etc.). For the 1-year analysis, we had 21 patients missing data for the DAPT duration, which did not allow us to assess if the prescription was complete or incomplete. These patients were not taken into account in the analysis.

The univariate model showed that women, individuals aged $>65$ years, patients with more comorbidities, patients with prior AMI, patients with LVEF $<40 \%$, and patients with multivessel coronary disease were at increased risk for incomplete prescription of guideline medications at discharge. The strongest predictor of incomplete prescription of guideline medications was transfer to cardiac surgery for CABG (OR 10.87, $p<0.005$ ). Indeed, from nine patients transferred to cardiac surgery, only two of them had a complete prescription of guideline medication at discharge, with P2Y12 inhibitor being the drug most often lacking. When all factors were entered together into a multivariate model, only female sex, active or former status as a smoker, LVEF $<40 \%$, patients with multivessel disease, and patients transferred to cardiac surgery remained significantly associated with incomplete adherence to guidelines at discharge $\left(\mathrm{OR}_{\mathrm{adj}}>2.0\right)$.

The univariate model identified fewer significant predictors of incomplete prescription after 1 year, with age $>65$ years, presence of a comorbidity, creatinine level $>110 \mu \mathrm{mol} / \mathrm{L}$ and $\mathrm{LVEF}<40 \%$ being significant factors. When all factors were entered in a multivariate model, age $>65$ years remained significantly associated with incomplete adherence to guidelines $\left(\mathrm{OR}_{\mathrm{adj}} 1.92, p=0.036\right)$. As all patients being transferred to cardiac surgery for CABG had an incomplete prescription after 1 year, this predictor could not be taken into account for the 1-year analysis.

\subsection{Readmission}

Among 301 patients with available data on readmission at 1 year, $73(24.3 \%)$ were readmitted within the year; 53 $(17.6 \%)$ were readmitted for a cardiovascular event or a cardiac procedure. Reasons for readmission are presented in Table S3 in the electronic supplementary material. Factors associated with emergency readmission for acute cardiovascular disease were tested with univariate logistic regression models (see Table $\mathrm{S} 4$ in the electronic supplementary material). Incomplete adherence to guidelines at discharge was not significantly associated with rate of readmission.

\section{Discussion}

We found high adherence to guidelines for the prescription of medications for STEMI patients. At discharge, $74.3 \%$ of patients had received an optimal drug prescription. After 1 year, the percentage had decreased to $49.1 \%$. These results are encouraging, but still show an incomplete implementation of secondary prevention drugs. The decrease in prescription rate within the year was most apparent for prescriptions

Table 3 Predictors of incomplete guideline adherence at discharge and after 1 year

\begin{tabular}{|c|c|c|c|c|c|c|c|c|c|c|c|c|}
\hline & \multicolumn{6}{|c|}{ Incomplete prescription at discharge } & \multicolumn{6}{|c|}{ Incomplete prescription at 1 year } \\
\hline & \multicolumn{3}{|c|}{$\begin{array}{l}\text { Univariate logistic regres- } \\
\text { sion }(n=352-358)\end{array}$} & \multicolumn{3}{|c|}{$\begin{array}{l}\text { Multivariate logistic regres- } \\
\text { sion }(n=332)\end{array}$} & \multicolumn{3}{|c|}{$\begin{array}{l}\text { Univariate logistic regres- } \\
\text { sion }(n=277-282)\end{array}$} & \multicolumn{3}{|c|}{$\begin{array}{l}\text { Multivariate logistic regres- } \\
\text { sion }(n=261)\end{array}$} \\
\hline & OR & $95 \% \mathrm{CI}$ & $P$ value & $\mathrm{OR}_{\mathrm{adj}}$ & $95 \% \mathrm{CI}$ & $P$ value & OR & $95 \% \mathrm{CI}$ & $P$ value & $\mathrm{OR}_{\mathrm{adj}}$ & $95 \% \mathrm{CI}$ & $P$ value \\
\hline Female sex & 1.81 & 1.07-3.07 & 0.026 & 2.54 & $1.29-5.02$ & 0.007 & 1.47 & $0.82-2.62$ & 0.195 & 1.16 & $0.59-2.30$ & 0.668 \\
\hline Age $>65$ yr & 2.27 & 1.39-3.69 & 0.001 & 1.22 & $0.64-2.33$ & 0.541 & 2.61 & $1.60-4.28$ & 0.000 & 1.92 & $1.04-3.53$ & 0.036 \\
\hline $\mathrm{BMI}>25 \mathrm{~kg} / \mathrm{m}^{2}$ & 0.87 & $0.54-1.42$ & 0.581 & 0.95 & $0.52-1.75$ & 0.878 & 0.69 & $0.42-1.12$ & 0.133 & 0.63 & $0.36-1.10$ & 0.106 \\
\hline Active/former smoker & 1.53 & $0.89-2.61$ & 0.123 & 2.29 & $1.16-4.50$ & 0.017 & 0.62 & $0.37-1.03$ & 0.064 & 0.91 & $0.51-1.62$ & 0.748 \\
\hline Dyslipidemia & 0.79 & $0.49-1.29$ & 0.353 & 0.75 & $0.41-1.39$ & 0.368 & 1.12 & $0.68-1.83$ & 0.662 & 1.10 & $0.62-1.94$ & 0.741 \\
\hline Diabetes & 1.21 & $0.63-2.34$ & 0.557 & 0.61 & $0.26-1.47$ & 0.276 & 0.74 & $0.36-1.53$ & 0.424 & 0.56 & $0.24-1.32$ & 0.185 \\
\hline Hypertension & 1.57 & $0.97-2.52$ & 0.065 & 1.08 & $0.57-2.05$ & 0.818 & 1.34 & $0.83-2.17$ & 0.230 & 0.96 & $0.53-1.75$ & 0.904 \\
\hline Comorbidity present & 1.71 & $1.05-2.78$ & $\mathbf{0 . 0 3 0}$ & 1.34 & $0.74-2.45$ & 0.337 & 1.88 & 1.12-3.17 & 0.017 & 1.70 & $0.94-3.08$ & 0.078 \\
\hline Creatinine $>110 \mu \mathrm{mol} / \mathrm{L}$ & 1.62 & $0.89-2.93$ & 0.107 & 1.50 & $0.70-3.22$ & 0.292 & 2.18 & $1.11-4.27$ & 0.023 & 1.69 & $0.78-3.67$ & 0.185 \\
\hline Prior AMI & 2.19 & $1.16-4.16$ & 0.016 & 1.66 & $0.73-3.76$ & 0.228 & 1.39 & $0.68-2.82$ & 0.365 & 1.32 & $0.57-3.05$ & 0.513 \\
\hline Prior $\mathrm{CABG}$ & 3.74 & $0.98-14.22$ & 0.053 & 2.53 & $0.49-12.90$ & 0.265 & 1.43 & $0.24-8.72$ & 0.695 & 1.13 & $0.16-8.14$ & 0.902 \\
\hline LVEF $<40 \%$ & 2.74 & $1.56-4.81$ & 0.000 & 2.49 & $1.27-4.85$ & 0.008 & 1.93 & $1.02-3.63$ & 0.043 & 1.70 & $0.83-3.48$ & 0.148 \\
\hline Multivessel disease & 2.40 & $1.42-4.05$ & 0.001 & 2.07 & $1.11-3.86$ & 0.022 & 0.92 & $0.57-1.48$ & 0.718 & 0.71 & $0.41-1.23$ & 0.225 \\
\hline Cardiac surgery transfer & 10.87 & $2.22-53.32$ & 0.003 & 9.66 & $1.46-63.75$ & 0.018 & 1.00 & na & na & 1.00 & na & na \\
\hline
\end{tabular}

Significant $P$ values $(<0.05)$ are in bold

$A M I$ acute myocardial infarction, $B M I$ body mass index, $C A B G$ coronary artery bypass grafting, $L V E F$ left ventricular ejection fraction, $n a$ not applicable 
of statins and P2Y12 inhibitors, with many patients reporting side effects as the reason for decreasing the drug dose, discontinuation of the drug, or switching to another drug entirely. This result highlights that STEMI patients suffer from side effects more frequently than patients enrolled in clinical studies. Our results show the difficulty of following guidelines in a real-life setting over the long term. Moreover, we showed that a drug that is not optimally prescribed at the time of discharge is rarely introduced within the year by general practitioners (GPs), except for ACEIs or ARBs. GPs are confident with the discharge prescription from specialists. These results show the importance of an optimal prescription at discharge and are supported by the literature, which largely showed an effect of optimal prescription at discharge on 1-year mortality after STEMI $[13,20]$.

Our results were consistent with the finding of other registries in Switzerland with a general high rate of prescription of recommended drugs [14]. Compared to registries from other countries, we found a better optimal prescription rate at discharge and at 1 year [20,21]. However, the results of registries are highly dependent on the method used to assess optimal drug prescription. A recent study conducted in the United States used the same method as we did (i.e., including contraindication assessment and statin dose) and showed similar results to ours, with an unexpected high adherence to guidelines [22]. We must be very aware of the method used for the assessment of outcomes before benchmarking and assessing the quality of care.

Multivariate analysis showed that patients with incomplete prescription of guideline medications at the time of discharge were more likely to be women and individuals with comorbidities and reduced LVEF. We also found that transfer to cardiac surgery was the strongest predictor of incomplete prescription of guideline medication. This last result is explained by the reluctance of surgeons to prescribe DAPT after CABG. Despite the fact guidelines recommend the use of DAPT after ACS requiring CABG [8, 23], surgeons from our institution fear pericardial blood effusion after surgery, and DAPT is still a subject of discussion.

The difference in prescription rate at discharge between men and women is consistent with previous studies [24, 25]. In our study population, we found that the disparity between men and women occurred mainly with the prescription of statins, women receiving more often medium- or low-intensity statin therapy than men $(24.7 \%$ vs $11.4 \%$ for men). The reasons for this gender disparity in the likelihood of receiving all recommended ACS prescriptions remain to be elucidated. Smolina et al. hypothesized that perceived risk for adverse outcomes after ACS is lower for young women because of a traditional school of thought dictating that cardiovascular disease is primarily a male disease [25]. However, clinical studies reported no difference by gender in terms of the safety or efficacy of any of the drugs after
ACS, and women should receive the same intensity of statin therapy as men [6].

At 1 year, elderly patients (i.e., $>65$ years) were more likely to have a suboptimal prescription. Older age is also already known as a risk factor for suboptimal prescription [24, 26-28]. We hypothesize that the disparity we found in our results is partly due to this perceived risk of MI recurrence and to the perceived risk of side effects, older patients being more likely to develop side effects due to polypharmacy [26]. However, Tomasevic et al. showed recently that the subgroup of older and comorbid patients with ACS benefit from an optimal post-ACS treatment, with a reduction in the 1-year mortality [13].

Finally, our findings suggest that clinicians are less aggressive with women and more fragile patients (elderly, comorbid patients, patients with reduced LVEF) than with individuals with fewer co-morbidities. We must therefore remind prescribers of the unequivocal benefits of secondary prevention in all of the STEMI population and encourage the prescription of optimal therapy to all patients.

Another important finding of our study is that BBs and ACEIs/ARBs were largely prescribed in the whole STEMI population. In patients with preserved LVEF, we found that $83.3 \%$ of patients received a BB and $94.2 \%$ received an ACEI/ARB at hospital discharge. However, the systematic use of these two classes of drugs in a modern population with a low prevalence of reduced ejection fraction is today questioned [29-31]. The reason is that studies proving their beneficial effects were conducted in the 1980s, prior to the implementation of new strategies of revascularization and the use of potent antithrombotic drugs and statins [32-38]. Several observational studies tried to assess the efficacy of BBs in the population with preserved LVEF, but results were contradictory, some studies showing a beneficial impact [39-42] and others not [29, 30, 43, 44]. Unfortunately, all these studies were based on registries with their known limitations. To this day, no randomized controlled trial has assessed the efficacy of BBs and ACEIs/ARBs for patients with preserved LVEF. As a consequence, current American and European guidelines still advocate the use of BBs and ACEIs/ARBs in all patients after STEMI, but with a class IIb level A and class IIa level A recommendation, respectively. The classes rise to I level A for patients with reduced LVEF $[12,45]$. The high rate of ACEI/ARB prescription in patients with preserved LVEF can be explained by the high prevalence of patients with hypertension, ACEI/ ARB being the first choice antihypertensive class post-AMI. BBs are also still widely prescribed, and the dose should in practice be up-titrated to the highest dose tolerated. This study does not address the doses of BB being prescribed, but we feel that they are often low and rarely up-titrated after discharge. This hypothesis could be addressed in a study dedicated to this subject. Therefore, the prescription of BB 
with low doses to patients with preserved LVEF could be questioned. At this time, there is no clear evidence in favor of their systematic use in the long term. However, the fear of ventricular arrhythmias as a complication of STEMI stays a strong argument in favor of BB prescription in the postinfarct period. We must now assess if BBs are still useful in the long term to reduce the morbi-mortality of STEMI patients. To drastically change the practice and have arguments to stop their prescription, we are now waiting for large randomized controlled trials to answer this question. In the meantime, cardiologists will probably remain careful and continue to prescribe these drugs in the whole STEMI population.

\subsection{Implication for Clinical Practice}

Although our study was conducted in a tertiary hospital and cannot be generalized to all centers, we were able to show that the prescription of an optimal medication regimen at discharge for STEMI patients was achievable. We reached a very high level of optimal prescription compared to other registries. In Switzerland, practitioners are in general disciplined to follow guidelines. Additionally, Switzerland is a small country with a highly developed healthcare system; information is then easily passed through different hospitals. Nevertheless, in modern healthcare, quality of care is becoming increasingly important, and our scope would be to reach a $100 \%$ rate of optimal prescription. Therefore, to reach a $100 \%$ rate of prescription at discharge, we plan to introduce a standardized prescription for all STEMI patients, with a reason for nonprescription being mandatory in the discharge letter. This will automatically reduce the rate of suboptimal prescription at discharge, and it will also give information to the GP about the reason for the lack of a medication. This will then allow the GP to rethink the whole prescription over the long term and reduce the rate of suboptimal prescription.

\subsection{Limitations and Bias}

The major limitation of our study is the small study population. Our hospital is a referral center in a small part of Switzerland. However, this study will allow centers to make a benchmark for quality of care of STEMI patients.

Another limitation of our study is the presence of a recall bias. We assessed the prescriptions provided at 1-year follow-up with a call to the patient, rather than the prescriber. Patients were asked to report on the previous 1-year period and likely provided incomplete information. We tried to minimize this phenomenon by asking patients to read what was written in their drug packages or by contacting the physician when the patient had any doubt about the accuracy of their reporting. Reasons for non-prescription at 1 year were also difficult to assess. Patients did not know reasons for a drug withdrawal from their practitioner, which resulted in a lot of unknown reasons in our results. Selection bias may also have colored the results presented above, suggested by a higher proportion of young patients that were lost to follow-up. Younger patients being not retired have less time to devote to support of a clinical study.

\section{Conclusion}

The present results provided information about the care provided for STEMI patients in a real-life clinical setting. The data collected showed that recommended medications were prescribed with high frequency at discharge $(74.3 \%)$ and decreased at 1 year $(49.1 \%)$. We also showed that patients most likely to receive a suboptimal prescription were women, elderly, and patients with comorbidities. We must therefore attempt to reduce the frequency of prescription errors at the time of discharge and implement a standardized prescription for all patients. Establishing such preventive measures should improve the quality of care provided to STEMI patients.

Funding No external funding was used to conduct this study/prepare this article.

\section{Compliance with Ethical Standards}

Conflict of interest All authors have completed the International Committee of Medical Journal Editors (ICMJE) Form for Disclosure of Potential Conflicts of Interest. Christel Bruggmann, Juan Fernando Iglesias, Rachel Fesselet, Marianne Gex-Fabry, Farshid Sadeghipour, Pierre Vogt and Pierre Voirol declare that they have no potential conflicts of interest that might be relevant to the contents of this article.

Informed consent Informed consent was obtained from all individual participants included in the study.

Open Access This article is distributed under the terms of the Creative Commons Attribution-NonCommercial 4.0 International License (http://creativecommons.org/licenses/by-nc/4.0/), which permits any noncommercial use, distribution, and reproduction in any medium, provided you give appropriate credit to the original author(s) and the source, provide a link to the Creative Commons license, and indicate if changes were made.

\section{References}

1. Nichols M, Townsend N, Scarborough P, Rayner M. Cardiovascular disease in Europe 2014: epidemiological update. Eur Heart J. 2014;35(42):2929. https://doi.org/10.1093/eurheartj/ehu378.

2. Benjamin EJ, Virani SS, Callaway CW, Chamberlain AM, Chang AR, Cheng S, et al. Heart disease and stroke statistics-2018 update: a report from the American Heart Association. Circulation. 2018;137(12):e67-492. https://doi.org/10.1161/CIR.00000 00000000558 . 
3. Hasdai D, Behar S, Wallentin L, Danchin N, Gitt AK, Boersma E, et al. A prospective survey of the characteristics, treatments and outcomes of patients with acute coronary syndromes in Europe and the Mediterranean basin; the Euro Heart Survey of Acute Coronary Syndromes (Euro Heart Survey ACS). Eur Heart J. 2002;23(15):1190-201.

4. Roe MT, Messenger JC, Weintraub WS, Cannon CP, Fonarow GC, Dai D, et al. Treatments, trends, and outcomes of acute myocardial infarction and percutaneous coronary intervention. J Am Coll Cardiol. 2010;56(4):254-63. https://doi.org/10.1016/j. jacc.2010.05.008.

5. Yan AT, Tan M, Fitchett D, Chow CM, Fowlis RA, McAvinue TG, et al. One-year outcome of patients after acute coronary syndromes (from the Canadian Acute Coronary Syndromes Registry). Am J Cardiol. 2004;94(1):25-9. https://doi.org/10.1016/j.amjca rd.2004.03.024.

6. Mukherjee D, Fang J, Chetcuti S, Moscucci M, Kline-Rogers E, Eagle KA. Impact of combination evidence-based medical therapy on mortality in patients with acute coronary syndromes. Circulation. 2004;109(6):745-9. https://doi.org/10.1161/01.CIR.00001 12577.69066.CB.

7. Ho PM, Spertus JA, Masoudi FA, Reid KJ, Peterson ED, Magid DJ, et al. Impact of medication therapy discontinuation on mortality after myocardial infarction. Arch Intern Med. 2006;166(17):1842-7. https://doi.org/10.1001/archi nte.166.17.1842

8. Kolh P, Windecker S, Alfonso F, Collet JP, Cremer J, Falk V, et al. ESC/EACTS Guidelines on myocardial revascularization: the Task Force on Myocardial Revascularization of the European Society of Cardiology (ESC) and the European Association for Cardio-Thoracic Surgery (EACTS). Developed with the special contribution of the European Association of Percutaneous Cardiovascular Interventions (EAPCI). Eur J Cardio-thorac Surg. 2014;46(4):517-92. https://doi.org/10.1093/ejcts/ezu366.

9. O'Gara PT, Kushner FG, Ascheim DD, Casey DE Jr, Chung MK, de Lemos JA, et al. 2013 ACCF/AHA guideline for the management of ST-elevation myocardial infarction: executive summary: a report of the American College of Cardiology Foundation/American Heart Association Task Force on Practice Guidelines. Circulation. 2013;127(4):529-55. https://doi.org/10.1161/CIR.0b013 e3182742c84.

10. Hamm CW, Bassand JP, Agewall S, Bax J, Boersma E, Bueno $\mathrm{H}$, et al. ESC Guidelines for the management of acute coronary syndromes in patients presenting without persistent ST-segment elevation: the Task Force for the Management of Acute Coronary Syndromes (ACS) in Patients Presenting without Persistent STSegment Elevation of the European Society of Cardiology (ESC). Eur Heart J. 2011;32(23):2999-3054. https://doi.org/10.1093/ eurheartj/ehr236.

11. Smith SC Jr, Benjamin EJ, Bonow RO, Braun LT, Creager MA, Franklin BA, et al. AHA/ACCF secondary prevention and risk reduction therapy for patients with coronary and other atherosclerotic vascular disease: 2011 update: a guideline from the American Heart Association and American College of Cardiology Foundation endorsed by the World Heart Federation and the Preventive Cardiovascular Nurses Association. J Am Coll Cardiol. 2011;58(23):2432-46. https://doi.org/10.1016/j.jacc.2011.10.824.

12. Ibanez B, James S, Agewall S, Antunes MJ, Bucciarelli-Ducci C, Bueno H, et al. 2017 ESC Guidelines for the management of acute myocardial infarction in patients presenting with STsegment elevation: the Task Force for the Management of Acute Myocardial Infarction in Patients Presenting with ST-Segment Elevation of the European Society of Cardiology (ESC). Eur Heart J. 2018;39(2):119-77. https://doi.org/10.1093/eurheartj/ehx393.

13. Tomasevic D, El Khoury C, Subtil F, Dubien PY, Bochaton T, Serre P, et al. Effect of optimal medical therapy at discharge in patients with reperfused ST-segment elevation myocardial infarction on 1-year mortality (from the Regional RESCUe Registry). Am J Cardiol. 2018;121(4):403-9. https://doi.org/10.1016/j.amjca rd.2017.11.002.

14. Auer R, Gencer B, Raber L, Klingenberg R, Carballo S, Carballo D, et al. Quality of care after acute coronary syndromes in a prospective cohort with reasons for non-prescription of recommended medications. PLoS One. 2014;9(3):e93147. https://doi. org/10.1371/journal.pone.0093147.

15. Welker J, Auer R, Gencer B, Muller O, Cornuz J, Matter CM, et al. Hospital revascularisation capability and quality of care after an acute coronary syndrome in Switzerland. Swiss Med Wkly. 2016;146:w14275. https://doi.org/10.4414/smw.2016.14275.

16. Gencer B, Rodondi N, Auer R, Raber L, Klingenberg R, Nanchen $\mathrm{D}$, et al. Reasons for discontinuation of recommended therapies according to the patients after acute coronary syndromes. Eur J Intern Med. 2015;26(1):56-62. https://doi.org/10.1016/j. ejim.2014.12.014.

17. Jneid H, Addison D, Bhatt DL, Fonarow GC, Gokak S, Grady KL, et al. 2017 AHA/ACC clinical performance and quality measures for adults with ST-elevation and non-ST-elevation myocardial infarction: a report of the American College of Cardiology/American Heart Association Task Force on Performance Measures. Circ Cardiovasc Qual Outcomes. 2017. https://doi.org/10.1161/ hcq.0000000000000032.

18. Schiele F, Gale CP, Bonnefoy E, Capuano F, Claeys MJ, Danchin $\mathrm{N}$, et al. Quality indicators for acute myocardial infarction: a position paper of the Acute Cardiovascular Care Association. Eur Heart J Acute Cardiovasc Care. 2017;6(1):34-59. https://doi. org/10.1177/2048872616643053.

19. Summary of recommendation statements. Kidney Int Suppl. 2012;2(1):8-12. https://doi.org/10.1038/kisup.2012.7.

20. Hoedemaker NPG, Damman P, Ottervanger JP, Dambrink JHE, Gosselink ATM, Kedhi E, et al. Trends in optimal medical therapy prescription and mortality after admission for acute coronary syndrome: a 9-year experience in a real-world setting. Eur Heart J Cardiovasc Pharmacother. 2018;4(2):102-10. https://doi. org/10.1093/ehjcvp/pvy005.

21. Chen HY, Saczynski JS, Lapane KL, Kiefe CI, Goldberg RJ. Adherence to evidence-based secondary prevention pharmacotherapy in patients after an acute coronary syndrome: a systematic review. Heart Lung J Crit Care. 2015;44(4):299-308. https://doi. org/10.1016/j.hrtlng.2015.02.004.

22. Fox AN, Skrepnek GH, Miller JL, Schwier NC, Ripley TL. Optimal medical therapy prescribing patterns and disparities identified in patients with acute coronary syndromes at an academic medical center in an area with high coronary heart disease-related mortality. Am J Cardiovasc Drugs. 2018. https://doi.org/10.1007/s4025 6-018-0308-x.

23. Kulik A, Ruel M, Jneid H, Ferguson TB, Hiratzka LF, Ikonomidis JS, et al. Secondary prevention after coronary artery bypass graft surgery: a scientific statement from the American Heart Association. Circulation. 2015;131(10):927-64. https://doi.org/10.1161/ CIR.0000000000000182.

24. Nguyen HL, Goldberg RJ, Gore JM, Fox KA, Eagle KA, Gurfinkel $\mathrm{EP}$, et al. Age and sex differences, and changing trends, in the use of evidence-based therapies in acute coronary syndromes: perspectives from a multinational registry. Coron Artery Dis. 2010;21(6):336-44. https://doi.org/10.1097/MCA.0b013e3283 $3 \mathrm{ce} 07 \mathrm{c}$.

25. Smolina K, Ball L, Humphries KH, Khan N, Morgan SG. Sex disparities in post-acute myocardial infarction pharmacologic treatment initiation and adherence: problem for young women. Circ Cardiovasc Quality and Outcomes. 2015;8(6):586-92. https ://doi.org/10.1161/CIRCOUTCOMES.115.001987. 
26. Tran CT, Laupacis A, Mamdani MM, Tu JV. Effect of age on the use of evidence-based therapies for acute myocardial infarction. Am Heart J. 2004;148(5):834-41. https://doi.org/10.1016/j. ahj.2003.11.028.

27. Ruiz-Bailen M, Aguayo de Hoyos E, Ramos-Cuadra JA, DiazCastellanos MA, Issa-Khozouz Z, Reina-Toral A, et al. Influence of age on clinical course, management and mortality of acute myocardial infarction in the Spanish population. Int J Cardiol. 2002;85(2-3):285-96.

28. Skolnick AH, Alexander KP, Chen AY, Roe MT, Pollack CV Jr, Ohman EM, et al. Characteristics, management, and outcomes of 5,557 patients age $>$ or $=90$ years with acute coronary syndromes: results from the CRUSADE Initiative. J Am Coll Cardiol. 2007;49(17):1790-7. https://doi.org/10.1016/j.jacc.2007.01.066.

29. Dahl Aarvik M, Sandven I, Dondo TB, Gale CP, Ruddox V, Munkhaugen J, et al. Effect of oral beta-blocker treatment on mortality in contemporary post-myocardial infarction patients: a systematic review and meta-analysis. Eur Heart J Cardiovasc Pharmacother. 2019;5(1):12-20. https://doi.org/10.1093/ehjcvp/ pvy034.

30. Dondo TB, Hall M, West RM, Jernberg T, Lindahl B, Bueno H, et al. beta-Blockers and mortality after acute myocardial infarction in patients without heart failure or ventricular dysfunction. $\mathrm{J}$ Am Coll Cardiol. 2017;69(22):2710-20. https://doi.org/10.1016/j. jacc.2017.03.578.

31. Nishino T, Furukawa Y, Kaji S, Ehara N, Shiomi H, Kim K, et al. Distinct survival benefits of angiotensin-converting enzyme inhibitors/angiotensin II receptor blockers in revascularized coronary artery disease patients according to history of myocardial infarction. Circ J. 2013;77(5):1242-52.

32. Dargie HJ. Effect of carvedilol on outcome after myocardial infarction in patients with left-ventricular dysfunction: the CAPRICORN randomised trial. Lancet. 2001;357(9266):1385-90.

33. Herlitz J, Elmfeldt D, Hjalmarson A, Holmberg S, Malek I, Nyberg G, et al. Effect of metoprolol on indirect signs of the size and severity of acute myocardial infarction. Am J Cardiol. 1983;51(8):1282-8.

34. Pedersen TR. Six-year follow-up of the Norwegian multicenter study on timolol after acute myocardial infarction. N Engl J Med. 1985;313(17):1055-8. https://doi.org/10.1056/NEJM198510 243131705.

35. Ryden L, Ariniego R, Arnman K, Herlitz J, Hjalmarson A, Holmberg $\mathrm{S}$, et al. A double-blind trial of metoprolol in acute myocardial infarction. Effects on ventricular tachyarrhythmias. N Engl J Med. 1983;308(11):614-8. https://doi.org/10.1056/nejm198303 173081102.

36. The Acute Infarction Ramipril Efficacy (AIRE) Study Investigators. Effect of ramipril on mortality and morbidity of survivors of acute myocardial infarction with clinical evidence of heart failure. Lancet. 1999;342(8875):821-8.
37. Gruppo Italiano per lo Studio della Sopravvivenza nell'infarto Miocardico. GISSI-3: effects of lisinopril and transdermal glyceryl trinitrate singly and together on 6-week mortality and ventricular function after acute myocardial infarction. Lancet. 1994;343(8906):1115-22.

38. ISIS-4 (Fourth International Study of Infarct Survival) Collaborative Group. ISIS-4: a randomised factorial trial assessing early oral captopril, oral mononitrate, and intravenous magnesium sulphate in 58,050 patients with suspected acute myocardial infarction. Lancet. 1995;345(8951):669-85.

39. Konishi H, Miyauchi K, Kasai T, Tsuboi S, Ogita M, Naito R, et al. Long-term effect of beta-blocker in ST-segment elevation myocardial infarction in patients with preserved left ventricular systolic function: a propensity analysis. Heart Vessels. 2016;31(4):441-8. https://doi.org/10.1007/s00380-014-0624-2.

40. Raposeiras-Roubin S, Abu-Assi E, Redondo-Dieguez A, Gonzalez-Ferreiro R, Lopez-Lopez A, Bouzas-Cruz N, et al. Prognostic benefit of beta-blockers after acute coronary syndrome with preserved systolic function. Still relevant today? Revista espanola de cardiologia (English ed). 2015;68(7):585-91. https://doi. org/10.1016/j.rec.2014.07.028.

41. Kernis SJ, Harjai KJ, Stone GW, Grines LL, Boura JA, O’Neill WW, et al. Does beta-blocker therapy improve clinical outcomes of acute myocardial infarction after successful primary angioplasty? J Am Coll Cardiol. 2004;43(10):1773-9. https://doi. org/10.1016/j.jacc.2003.09.071.

42. Freemantle N, Cleland J, Young P, Mason J, Harrison J. beta Blockade after myocardial infarction: systematic review and meta regression analysis. BMJ. 1999;318(7200):1730-7.

43. Huang BT, Huang FY, Zuo ZL, Liao YB, Heng Y, Wang PJ, et al. Meta-analysis of relation between oral beta-blocker therapy and outcomes in patients with acute myocardial infarction who underwent percutaneous coronary intervention. Am J Cardiol. 2015;115(11):1529-38. https://doi.org/10.1016/j.amjca rd.2015.02.057.

44. Ozasa N, Kimura T, Morimoto T, Hou H, Tamura T, Shizuta $\mathrm{S}$, et al. Lack of effect of oral beta-blocker therapy at discharge on long-term clinical outcomes of ST-segment elevation acute myocardial infarction after primary percutaneous coronary intervention. Am J Cardiol. 2010;106(9):1225-33. https://doi. org/10.1016/j.amjcard.2010.06.048.

45. O'Gara PT, Kushner FG, Ascheim DD, Casey DE Jr, Chung MK, de Lemos JA, et al. 2013 ACCF/AHA guideline for the management of ST-elevation myocardial infarction: a report of the American College of Cardiology Foundation/American Heart Association Task Force on Practice Guidelines. Circulation. 2013;127(4):e362-425. https://doi.org/10.1161/CIR.0b013e3182 $742 \mathrm{cf} 6$.

\section{Affiliations}

\section{Christel Bruggmann ${ }^{1,2}(0)$ Juan F. Iglesias ${ }^{3} \cdot$ Marianne Gex-Fabry $^{4} \cdot$ Rachel Fesselet $^{5} \cdot$ Pierre Vogt $^{5}$. Farshid Sadeghipour $^{1,2} \cdot$ Pierre Voirol $^{1,2}$}

1 Service of Pharmacy, Lausanne University Hospital and University of Lausanne, Lausanne, Switzerland

2 School of Pharmaceutical Sciences, University of Geneva, University of Lausanne, Geneva, Switzerland

3 Service of Cardiology, Geneva University Hospital, Geneva, Switzerland
4 University of Geneva, Geneva, Switzerland

5 Service of Cardiology, Lausanne University Hospital and University of Lausanne, Lausanne, Switzerland 